International Journal of Home Science 2021; 7(2): 08-10

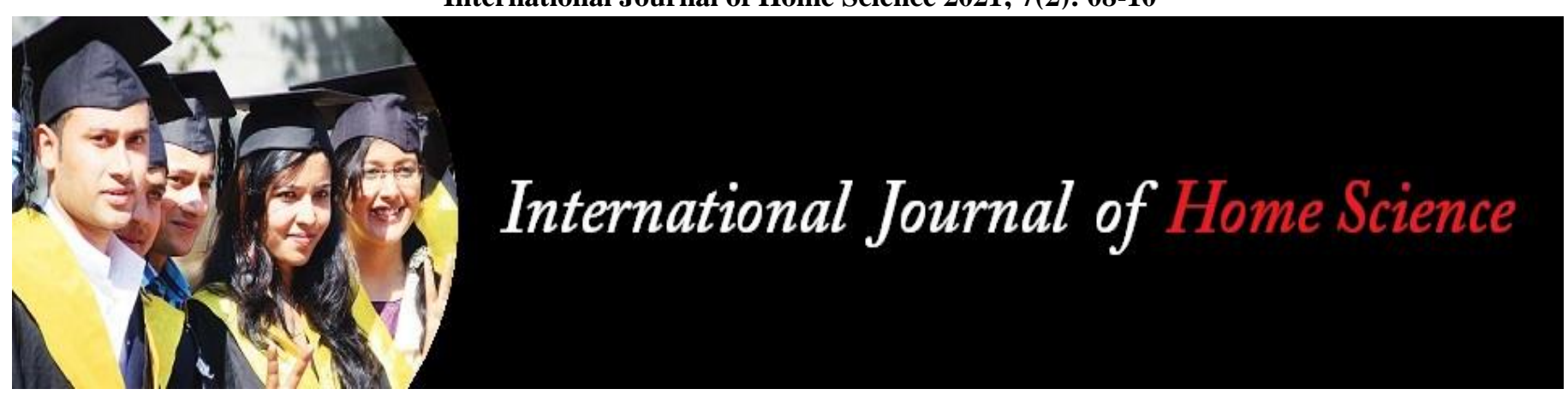

ISSN: $2395-7476$

IJHS 2021; 7(2): 08-10

(C) 2021 IJHS

www.homesciencejournal.com

Received: 04-03-2021

Accepted: 06-04-2021

डॉ. दीपा स्वामी

सह आचार्य गृहविज्ञान विभाग

राजकीय कला कन्या महाविद्यालय,

कोटा, राजस्थान, भारत
Corresponding Author:

डॉ. दीपा स्वामी

सह आचार्य गहविज्ञान विभाग

राजकीय कला कन्या महाविद्यालय,

कोटा, राजस्थान, भारत

\section{छात्राओं में ई-लर्निंग की जानकारी पर एक अध्ययन}

\section{डॉ. दीपा स्वामी}

DOI: https://doi.org/10.22271/23957476.2021.v7.i2a.1139

\section{सारांश}

आज हम डिजीटल युग में जीवनयापन कर रहे हैं। प्रातःकालीन से रात्रि तक हम मोबाईल फोन, टेबलेट, आईपैड, सोशल मीडिया आदि में व्यस्त रहते हैं। परन्तु इस नवीन युग में प्रवेश के मूल में शिक्षा की ही भूमिका है। शिक्षा के मुख्य उद्देश्यों को प्राप्त करने में लर्निंग (अधिगम) का महत्वपूर्ण स्थान है।समय के साथ सीखने की प्रक्रियाओं में परिवर्तन आया है। ई-लर्निंग एक ऐसी प्रक्रिया है जिसमें पारम्परिक कक्षा-कक्ष न होकर पाठ्यक्रम व प्रोग्राम ऑनलाइन होते हैं। तकनीकी के इस युग में युवा वर्ग का बहुत समय इलेक्ट्रोनिक मीडिया पर गुजरता है।

आज कई विद्यार्थी अपने विषयों को ऑनलाइन पढ़ते हैं। ई-लर्निंग में हम जब चाहे तब जानकारी प्राप्त कर सकते हैं। छात्रवर्ग में ई-लर्निंग को लेकर काफी दिलचस्पी है। ई-लर्निंग के प्रोत्साहन से शिक्षा सुविधाओं के विस्तार तथा गुणवत्तापूर्ण शिक्षा के ध्येय प्राप्ति में सहायक है।

प्रस्तुत अध्याय से पता चलता है कि स्मार्टफोन, इन्टरनेट, वाई-फाई जैसी तकनीक व्यावहारिक रूप से सभी को सस्ती दरों पर उपलब्ध होने के कारण शिक्षा के क्षेत्र में ई-लर्निंग का प्रयोग काफी लोकप्रिय हो रहा है। अध्ययन में सम्मिलित अधिकतर छात्राओं को ई-लर्निंग से सम्बन्धित जानकारी थी, परन्तु ई-लर्निंग का उपयोगन अपनी औपचारिक शिक्षा में करने को लेकर वे सहज नहीं थे। ई-लर्निंग द्वारा सीखना ज्यादा आसान व लचीला होता है, क्योंकि एक विषय को सिखाने के लिए विभिन्न तकनीकों का उपयोग होता है।

कुटशब्द: छात्राओं, ई-लर्निंग, शिक्षा

\section{प्रस्तावना}

21 वीं शताब्दी तकनीकी दृष्टिकोण से बहुत प्रभावशाली सिद्ध हो रही है। यह हर उसका स्वागत कर रही है जो तकनीकी के विकास में सहायक है, इसका सबसे बढ़िया उदाहरण है- ई-लर्निंग। जो कि कोविड-19 की महामारी में शिक्षक एवं विद्यार्थी हेतु अत्यन्त लाभदायक साबित हुआ है।

ई-लर्निंग का मतलब "इलेक्ट्रॉनिक लर्निंग" अर्थात इलेक्ट्रॉनिक डिवाइस और डिजिटल मीडिया के माध्यम से शिक्षा ग्रहण करना। इसे मुख्य रूप से दो भागों में विभाजित किया जा सकता है -

(अ) समकालिक (Synchronous) (ब) असमकालिक (Asynchronous)

अ. समकालिक: इसका तात्पर्य है कि "एक ही समय में“। समकालिक अधिगम में सीखने व सिखाने वाला अलग-अलग स्थानों से एक ही समय में सहभागिता करते हैं, जिसमें सीखने वाला अपने सवालों की पूछकर अपनी शंकाओं का समाधान तुरन्त ही समस्याओं का समाधान कर लेते हैं। इसीलिए इसे (Real time learning) "तुरन्त सीखना" भी कहते हैं।

ब. असमकालिक: इसका तात्पर्य है कि "एक समय में नहीं“। असमकालिक लर्निंग में सीखने और सिखाने वाले के बीच वास्तविक समय में सहभागिता करने की कोई अवधारणा नहीं है। असमकालिक लर्निंग में जानकारी पहले से ही मोजूद रहती है जिससे सीखने वाले अपनी सुविधा के अनुसार पढ़ सकता है। इसमें समय की कोई पाबंदी नहीं रहती है।

ई-लर्निंग के प्रसार व गुणवत्तापूर्ण शिक्षा प्रदान करने की दृष्टि से एक उपयुक्त व्यवस्था है। बिना किसी भेदभाव के सभी के लिए उपलब्ध होने वाली शिक्षा है। वर्तमान मे यह सर्वाधिक कम लागत की कुशल तकनीक है जो सभी शिक्षार्थियों की आवश्यकताओं को पूरा करने में सक्षम है। कक्षा में शिक्षक द्वारा किसी पाठ को पढ़ाने के बाद बार-बार उसका दोहरान नहीं हो सकता है जबकि ई-लर्निंग में तैयार पाठ छात्र बार-बार अपनी सुविधानुसार व समझ की क्षमतानुसार ग्रहण कर सकता है। 
ई-लर्निंग की सुविधा के कारण छात्र नवीनतम जानकारियों से परिचित रहता है। ई-लर्निंग से धन की भी बचत होती है क्योंकि पाठ्यक्रम ऑनलाईन उपलब्ध होने के कारण पुस्तकों व अन्य शिक्षण सामग्री पर खर्च नहीं करना पड़ता है। ई-लर्निंग उन विद्यार्थियों के लिए वरदान बन गया है जो किसी कारणवश स्कूल व कॉलेज जाने में सक्षम नहीं है।

ई-लर्निंग की हानियाँ: अगर आप सीखने को लेकर गम्भीर है तो ऑनलाईन लर्निंग में कोई परेशानी नहीं है परन्तु आप में स्वयं अनुशासन नहीं है, बिना कहे आप पढ़ाई नहीं करते तो ई-लर्निंग में उन्हें पढ़ाई करने के लिए कहने वाला कोई नहीं होगा। ई-लर्निंग कभी भी आपको स्कूल कक्षा जैसा सीखने का वातावरण नहीं दे सकता है जिसमें आप शिक्षक के साथ आमने-सामने सहभागिता कर सकें। स्क्रीन द्वारा पढ़ने की बजाय पेपर द्वारा पढ़ना अधिक अहम है क्योंकि जब व्यक्ति पेपर पढ़ता है तब विषयवस्तु का मानसिक चित्रण उसके मस्तिष्क पर हो जाता है। बहुत ज्यादा देर तक स्क्रीन पर पढ़ने से आँखों पर विपरीत प्रभाव पड़ता है।

उद्देश्य: सरकारी महाविद्यालय की 17-21 वर्ष की कला, वाणिज्य और विज्ञान स्नातक छात्राओं से ई-लर्निंग के बारे में जानकारी प्राप्त करना।

शोध विधि: यह अध्ययन राजस्थान के कोटा क्षेत्र के राजकीय महाविद्यालयों में किया गया।

शोध के उद्देश्यों को ध्यान में रखते हुए कोटा शहर की राजकीय महाविद्यालयों की छात्राओं का चयन निदर्शन विधि द्वारा किया गया। चूँकि शोधार्थी का मूल निवास स्थान कोटा है। अतः अध्ययन हेतु कोटा जिले का चयन किया गया। इस अध्ययन के लिए 17-21 वर्ष की छात्राओं को चुना गया।

शोध के उद्देश्य व नमूनों को ध्यान में रखते हुए शोध में प्रश्नावली विधि का चयन सही व व्यवहारिक है। प्रश्नावली की एक क्रमबद्ध सूची होती है जो अध्ययन विषय से सम्बन्धित प्राथमिक तथ्यों को संकलित करने के लिए प्रयोग में लायी जाती है। प्रश्नावली को सम्बन्धित विषय विशेषज्ञों से जांच करवायी गई जिसमें उनके द्वारा दिए गए सुझावों के अनुसार संशोधन करके प्रश्नावली तैयार की गई।

तथ्यों का संकलन हेतु प्रश्नावली विधि में 20 प्रश्न रखे गये है जिसमें सभी 20 प्रश्न सहमत और असहमत से सम्बन्धित हैं। उन्हीं में से एक विकल्प चुनकर उत्तरदाताओं को अपना मत प्रस्तुत करना होगा। प्रश्नावली अनुसूची के माध्यम से प्राप्त तथ्यों को सारणीबद्ध करके विश्लेषण किया गया। परिणाम प्रतिशत विधि से प्राप्त किया गया।

परिणाम एवं परिचर्चाः ई-लर्निंग के बारे में $92 \%$ छात्राओं को जानकारी है और $8 \%$ छात्राओं को इस बात से असहमति हैं। शोधार्थी का मानना है कि मोबाइल का ज्यादा इस्तेमाल करने से और इंटरनेट डाटा के सस्ते होने से $92 \%$ छात्राओं को ई-लर्निंग की जानकारी है और $8 \%$ छात्राएँ ग्रामीण क्षेत्र में रहने के कारण ई-लर्निंग से परिचित नहीं हैं। ई-लर्निंग ऑनलाईन शिक्षा का एक अच्छा विकल्प है, इस मत से $70 \%$ छात्राऐं सहमत और $30 \%$ छात्राऐं असहमत हैं। शोधार्थी का मानना है कि कई ऐसी जानकारियाँ जिनके बारे में हमें पता नहीं होता उनकी जानकारी हमें ई-लर्निंग से हो जाती है।

ई-लर्निंग के माध्यम से पढ़ाई करना पसन्द करते हैं तो $78 \%$ छात्राओं को पसन्द है और $22 \%$ छात्राऐं इस मत से असहमत हैं। शोधार्थी का मानना है कि आज अगर किसी भी क्षेत्र के बारे में जानकारी चाहिए तो उसे इन्टरनेट पर खोज सकते हैं। हम अपनी सुविधानुसार कहीं भी और कभी भी जानकारी प्राप्त कर सकते हैं। ई-लर्निंग का उपयोग अपनी औपचारिक शिक्षा में करते हैं तो
$54 \%$ छात्राओं ने सहमत और $46 \%$ छात्राओं ने असहमत में जवाब दिया। शोधार्थी का मानना है कि यह तकनीक सहज उपलब्ध हो रही है और इस तकनीक के द्वारा किसी भी विषय को जल्दी व आसानी से समझने में मदद मिलती है। ई-लर्निंग पारम्परिक शिक्षा से बेहतर है तो $34 \%$ छात्राओं ने सहमत और $66 \%$ छात्राओं ने असहमत में जवाब दिया। शोधार्थी का मानना है कि पारम्परिक शिक्षा के मुकाबले ई-लर्निंग से सीखना ज्यादा आसान और लचीला है क्योंकि किसी भी विषय को कई बार समझा जा सकता है। पारम्परिक शिक्षा की तरह अपनी समस्याओं का समाधान तुरन्त ही नहीं किया जा सकता है। ई-लर्निंग दूरस्थ शिक्षा प्राप्त करने वाले विद्यार्थियों के लिए एक बेहतर विकल्प है तो $88 \%$ छात्राओं ने इससे सहमति जताई और $12 \%$ छात्राओं ने असहमति में जवाब दिया। शोधार्थी के लिए वरदान साबित हुआ है जो किसी वजह से कॉलेज नहीं जा पाते हैं वे घर पर ही ई-लर्निंग द्वारा अपने विषय से सम्बन्धित जानकारी प्राप्त कर लेते हैं।

ई-लर्निंग औपचारिक शिक्षण विधियों की तुलना में पाठ्यक्रम को बेहतर समझने में मदद करता है तो $46 \%$ छात्राओं ने सहमत और $54 \%$ छात्राओं ने असहमत में जवाब दिया। शोधार्थी का मानना है कि ई-लर्निंग में एक ही विषय को सिखाने के लिए विभिन्न तकनीकों का उपयोग किया जाता है जैसे- ऑडियो, विडियो, क्विज इत्यादि। ई-लर्निंग द्वारा किसी भी विषय को रोचक तरीके से सीखा जा सकता है। ई-लर्निंग उपयोगी है क्योंकि पाठ्यक्रम ऑनलाइन उपलब्ध हैं तो इससं $72 \%$ छात्राओं ने सहमत और $28 \%$ छात्राओं ने असहमत में जवाब दिया। शोधार्थी का मानना है कि ई-लर्निंग उपयोगी है क्योंकि यह ऑफलाईन संसाधनों की कमी पूरी करता है। ई-लर्निंग विद्यार्थियों को सीखने की प्रेरणा को प्रभावित करती है तो इससे $38 \%$ छात्राओं ने सहमति और $62 \%$ छात्राओं ने असहमति में जवाब दिया। शोधार्थी का मानना है कि तकनीकी और ऑनलाईन लर्निंग सिस्टम में सुधान होने, इस पद्धति के लचीले हो जाने के कारण कई कॉलेज में भी ई-क्लासरूम को बढावा दिया जा रहा है।

ई-लर्निंग अधिगम में ई-लर्निंग के प्रवेश के पश्चात् सकारात्मक बदलाव आया है तो $40 \%$ छात्राऐं इस मत से सहमत और $60 \%$ छात्राओं ने असहमति में जवाब दिया। शोधार्थी का मानना है कि वर्तमान में कम्प्यूटर तकनीकें आ जाने के कारण एक अलग ही प्रकार की लर्निंग थ्योरी इलेक्ट्रोनिक्स डिवाइस द्वारा प्राप्त की जा रही है। ई-लर्निंग के आ जाने के बाद छात्र पारम्परिक कक्षाओं से दूर हो गये हैं, तो $36 \%$ छात्राऐं इस मत से सहमत है और $64 \%$ छात्राओं ने असहमत में जवाब दिया। शोधार्थी का मानना है कि वर्तमान में कम्प्यूटर और मोबाइल फोन के अधिक उपयोग के कारण छात्राएँ ई-लर्निंग द्वारा सीखने में अधिक दिलचस्पी लेती हैं क्योंकि किसी भी विषय को कई बार देख व सुनकर समझ सकते हैं।

ई-लर्निंग आने वाले समय में औपचारिक शिक्षण का स्थान ले सकता है तो इस मत से $34 \%$ छात्राओं ने सहमत और $66 \%$ छात्राओं ने असहमत में जवाब दिया। शोधार्थी का मानना है कि वर्तमान में टेक्नोलॉजी का जिस तरह से प्रचार-प्रसार हो रहा है और कई शिक्षण संस्थानों में ना बैग, ना बुक्स व डिजिटल क्लासरूम जैसी सुविधा कर दी है जिसे देखकर लगता है कि ई-लर्निंग को आने वाले समय में बढ़ावा मिल सकता है। ई-लर्निंग के आ जाने के बाद छात्र पारम्परिक कक्षाओं से दूर हो गये है तो $36 \%$ छात्राओं ने सहमत और $64 \%$ छात्राओं ने असहमत में जवाब दिया। शोधार्थी का मानना है कि ई-लर्निंग के बढ़ते साधनों से सीखना और सिखाना काफी आसान हो गया है क्योंकि आप अपने कम्फर्ट के हिसाब से कहीं भी और कभी भी सीख सकते हैं। इसमें समय व स्थान की कोई पाबन्दी नहीं होती है।

ई-लर्निंग के उपयोग से शिक्षण प्रदर्शन में सुधार हुआ है तो $42 \%$ छात्राओं ने सहमत और $58 \%$ छात्राओं ने असहमत में जवाब दिया। शोधार्थी का मानना है कि ई-लर्निंग में एक ही विषय को सीखने के लिए विभिन्न तकनीकों का उपयोग होता है जैसे - ऑडियो, 
विडियो, गेम्स आदि जिससे शिक्षण रूचिकर बन जाता है और छात्र अपनी रूचि से किसी भी तकनीक का उपयोग कर सीख सकते हैं। ई-लर्निंग द्वारा पर्यावरण संरक्षण में मदद मिली है तो $34 \%$ छात्राओं ने सहमत और $66 \%$ छात्राओं ने असहमत में जवाब दिया। शोधार्थी का मानना है कि ई-लर्निंग को पर्यावरण के हिसाब से बढ़ावा मिला है क्योंकि यह एक पेपरलेस लर्निंग है। ई-लर्निंग में जानकारी को किताब की बजाय वेब में स्टोर किया जाता है जिससे पर्यावरण संरक्षण में मदद मिली है।

भविष्य में ई-लर्निंग शिक्षण का एक बेहतर विकल्प है तो $46 \%$ छात्राआकें ने सहमत और $54 \%$ छात्राओं ने असहमत में जवाब दिया। शोधार्थी का मानना है कि तेजी से बढ़ती टेक्नोलॉजी के कारण परम्परागत कक्षाओं में जाकर सीखने के मुकाबले ऑनलाइन सीखना ज्यादा आसान व लचीला बनता जा रहा है। इसलिए भविष्य में ई-लर्निंग परम्परागत शिक्षण के साथ जुड़कर शिक्षण का एक बेहतर साधन बनेगा।

अध्ययन के पश्चात् यह सुझाव दिया जा सकता है कि ई-लर्निंग को औपचारिक शिक्षण संस्थानों में ही उपलब्ध करवाई जाए ताकि विद्यार्थी नई तकनीक का उपयोग कर अपने कौशल को और बेहतर बनाने में सहायता ले सकें। साथ ही इस तकनीक का उपयोग करके वे अपने शिक्षण प्रदर्शन में सुधार कर सकें।

\section{संदर्भ ग्रन्थ सूची}

1. Dobrin J. Who is teaching online ITPE News, 1999;2(12):6-7

2. Naidu S. E- Learning: A Guidebook of Principles ,procedures and practices, $2^{\text {nd }}$ revised edition, CEMCA, 2006

3. McLeod D. E- Learning Tranning vs Instructor -Led Tranning San Franciso state University, ITEC 865, Professor Brain Beatty, USA, 2006.

4. https://www.learndash.com/3-types-of-elearning/

5. https://murcha.wordpress.com/2011/01/05/whyelearning-is-essential-for-students/

6. https://www.quora.com/in/What-is-the-importance-of-elearning

7. https://elearningindustry.com/9-benefits-of-elearning-forstudents 